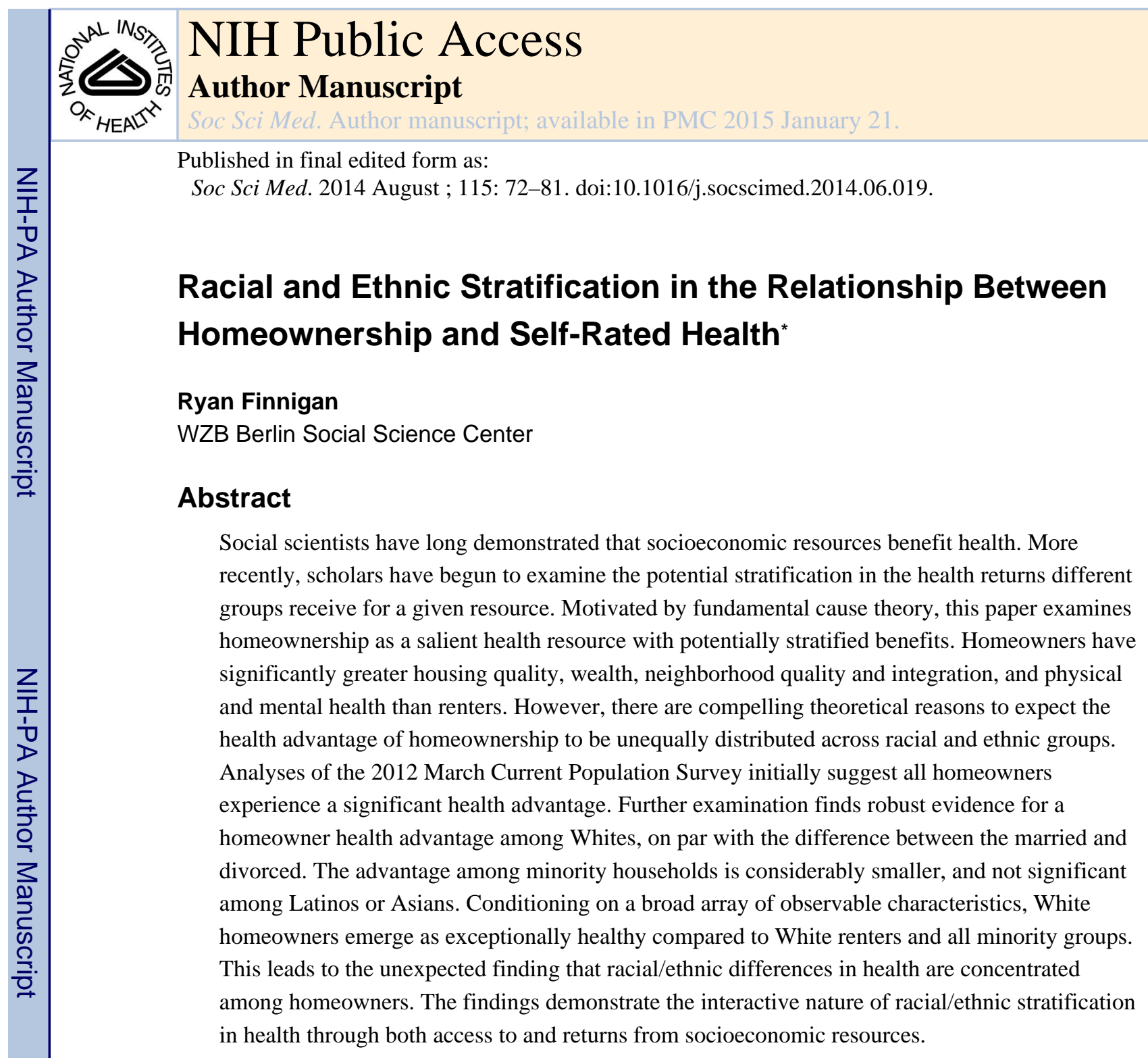

\title{
Keywords
}

Racial and Ethnic Stratification; Homeownership; Health Disparities; United States

\begin{abstract}
Homeownership has long been the symbol of the "American Dream" and has played a central role in defining success in American society. Homeownership has been associated with a broad set of social and economic advantages, ranging from greater wealth to higher life satisfaction (Dietz and Haurin 2003; Rossi and Weber 1996). Some studies also link homeownership to better physical and mental health (Dietz and Haurin 2003; Evans, Wells, and Moch 2003; Kearns et al. 2000; Macintyre et al. 1998; Manturuk 2012; Rossi and
\end{abstract}

\footnotetext{
*I gratefully acknowledge support for this research from the National Institute of Aging's Graduate and Post-Doctoral Training Grant through the Duke Population Research Institute (grant number 5T32-AG-000139-22, P.I.: Kenneth Land). This work benefited tremendously from generous guidance and reviews from David Brady and Linda George. Comments from Rebekah Burroway, Patricia Thomas, Megan Renolds, Andrew Miles, and Sowmya Rajan also improved the quality of the paper.

Please direct correspondence to: Ryan Finnigan, Wissenschaftszentrum Berlin für Sozialforschung, Reichpietschufer 50, D-10785, Berlin, Germany, Phone: +49 3025491 382, ryan.finnigan@wzb.eu.

A previous version of this paper was presented at the 2010 Annual Meetings of the American Sociological Association.
} 
Weber 1996). The literature suggests this is because homeownership confers higher perceptions of control and security, and residential stability and neighborhood integration (Dietz and Haurin 2003; Kearns et al. 2000; Rohe and Stewart 1996; Rossi and Weber 1996). Homeowners also have better average physical housing quality (Friedman and Rosenbaum 2004; Rosenbaum 1996) and much greater economic resources (Boehm and Schlottmann 2008).

Though past literature has focused on identifying the relative salience of the direct and indirect pathways through which homeownership may improve health, much less attention has been paid to potential stratification in this relationship. Homeownership is profoundly stratified by race and ethnicity, as is health. Approximately 74 percent of White households own their homes, compared to only 45 percent of Black and Latino households (U.S. Census Bureau 2013). Even after attaining homeownership, racial and ethnic minorities are also disadvantaged by large disparities in the social and economic returns to homeownership. Non-White homeowners are often restricted to houses in resource-poor neighborhoods, accumulate far less equity, and have disproportionately higher mortgage rates that increase the tenuousness of their residency (Boehm and Schlottmann 2004; Flippen 2001; Krivo and Kaufman 2004; Massey and Denton 1993; Yinger 1995). These inequalities give one reason to suspect that returns to homeownership might be stratified. Nevertheless, existing research has not thoroughly examined this possible racial and ethnic stratification in the health returns to homeownership.

This study scrutinizes homeownership as an important socioeconomic resource for health. Moreover, this study uniquely examines whether and how the health returns to this resource may be stratified for different racial and ethnic groups. Building on fundamental cause theory (Link and Phelan 1995) and prior research, the paper constructs hypotheses for the relationship between homeownership and health. I empirically evaluate the hypotheses for the US's four largest racial and ethnic groups using the March 2012 Current Population Survey (CPS). First, I provide a recent and nationally representative evaluation of homeowners' potential health advantage over renters. Second, I test whether any such health advantage is stratified by race/ethnicity, following sociological literature on racial and ethnic stratification. The findings indicate that homeowners have significantly better self-rated health than comparable renters. The relationship is robust to the inclusion of a variety of controls, consistent with the fundamental cause argument. However, the advantage applies primarily to Whites, and White homeowners are an exceptionally healthy group among the overall population. In contrast, Black homeowners have a much smaller health advantage over Black renters, and Latino and Asian homeowners have no significant advantage. These findings demonstrate the interactive nature of racial and ethnic stratification in the generation of health disparities.

\section{Homeownership and Health}

Link and Phelan's (1995) theory of fundamental causes posits that socioeconomic resources fundamentally affect health, regardless of specific diseases or health behaviors that operate as mechanisms. Homeownership may represent one such socioeconomic resource, which benefits health through multiple social and economic pathways. Past literature provides 
evidence that homeownership is beneficial for health through both direct pathways and indirect pathways. Direct pathways include homeowners' greater perceptions of control and security, and residential stability and social integration compared to renters (Dietz and Haurin 2003; Rohe and Stewart 1996; Rohe, Van Zandt, and McCarthy 2002; Rossi and Weber 1996). Indirect pathways include social and economic benefits associated with homeownership, but potentially attainable by other means besides homeownership. For instance, homeownership provides higher average housing quality (Friedman and Rosenbaum 2004), and a basis for wealth accumulation (Boehm and Schlottmann 2008).

The first direct pathway is homeowners' higher level of self-efficacy, self-satisfaction, and perceived control over life significant events (Rossi and Weber 1996). Homeowners experience higher levels of security and autonomy related to their physical homes (Kearns et al. 2000). This enhanced sense of control likely represents a buffer and coping resource for stressful events (Rohe and Stegman 1994a). Those with greater self-efficacy are more likely to select into homeownership. However, even among matched sets of low-income homeowners and renters, homeowners have significantly higher perceptions of control, higher life satisfaction and lower mental distress (Manturuk 2012; Rohe and Stegman 1994a).

Another potential direct pathway is homeowners' greater residential stability and neighborhood integration. Homeowners' longer lengths of residency are due to both selection and high transaction costs for buying and selling homes. Despite selection of more residentially stable households into homeownership, the greater difficulty for homeowners to move quickly and easily makes greater stability an intrinsic element of homeownership (Dietz and Haurin 2003; Rohe and Stewart 1996). Relatedly, homeowners are more likely than renters to be integrated into residentially stable neighborhoods with greater affluence, lower poverty, and better health service provision, all of which significantly benefit health (Dietz and Haurin 2003; Kawachi and Berkman 2003; Kirby 2008; Macintyre and Ellaway 2003). Homeowners are also more civically engaged in the local community, and express higher trust in their neighbors (McCabe 2013; Rohe and Stegman 1994b; Rossi and Weber 1996). The salience of this neighborhood integration for health by homeownership is somewhat unclear (Manturuk 2012). However, social cohesion and control, operationalized as collective efficacy (Sampson, Morenoff, and Gannon-Rowley 2002), are positively related to both individual health and local homeownership rates (Browning and Cagney 2002; Entwisle 2007; Sampson 2003).

Indirect pathways through which homeowners may experience health benefits include higher average housing quality, and greater wealth accumulation. Fewer homeowners than renters live in poor quality housing (Friedman and Rosenbaum 2004; Rosenbaum 1996). Dampness and mold lead to respiratory disease, pest infestations and infectious disease, and illness due to cold or heat exposure (Dunn 2000). Those living in poor quality housing report higher mental and emotional stress, and higher rates of diagnosed mental disorders due to overcrowding (Evans et al. 2000). Finally, homeowners are much more likely to live in single-family, detached homes. Residents of these houses report less mental distress and greater positive affect than residents of other structural types (see Evans, Wells, and Moch [(2003)] for a review). 
Homeowners experience far greater wealth accumulation through tax advantages and home equity. Wealth has been linked with lower mortality, higher self-rated health, fewer chronic conditions, higher functional status, and better mental health (see Pollack, et. al. [(2007)] for a review). Home equity accumulation and accompanying tax benefits form the foundation for most households' wealth accumulation. Second mortgages or home equity loans also provide a buffer against negative economic shocks (Dietz and Haurin 2003; Oliver and Shapiro 1995). Homeownership is a unique component of wealth because it is both an investment and consumption good, making it a higher priority for most households than other investments (Shlay 2006).

Overall, homeownership may be related to health through a complex array of direct and indirect pathways. Regardless of variation in particular mechanisms, homeownership likely represents a significant health resource consistent with fundamental cause theory (Link and Phelan 1995). These relationships motivate the first hypothesis.

\section{Hypothesis 1: Homeowners exhibit a significant health advantage over otherwise comparable renters}

Though a positive relationship between homeownership and physical and mental health has been previously demonstrated (Dietz and Haurin 2003; Manturuk 2012; Rossi and Weber 1996), the literature lacks an empirical evaluation of health differences between homeowners and renters in recent years. To the best of my knowledge, Rossi and Weber (1996) conducted the most recent nationally representative study for the US, using data from 1988 through 1993. Conversely, more recent studies investigating the pathways through which homeownership influences health lack representative data for the entire population. A recent and representative empirical examination may be particularly relevant in light of the recent housing and foreclosure crisis of the late 2000s.

\section{Racial/Ethnic Stratification in Homeownership and Health}

Fundamental cause theory also recognizes racial inequality as a social condition influencing health (Link and Phelan 1995). Racial stratification increases socioeconomic disadvantage and other risk factors for poor health among minorities relative to Whites. However, racial stratification may also undermine the health benefits of socioeconomic resources. If homeownership is a salient health resource, racial inequality in homeownership attainment would contribute to health disparities. However, racially unequal health returns to homeownership would compound and further intensify the salience of racial stratification to health disparities. In this sense, both socioeconomic resources and racial stratification would jointly be fundamental causes of disease.

Past research has thoroughly documented racial and ethnic stratification in access to homeownership. Racial and ethnic segregation to disadvantaged neighborhoods and housing markets (Flippen 2001; Massey and Denton 1993), lender and realtor discrimination (Rugh and Massey 2010), and lower inter-generational wealth transmission for down payments (Oliver and Shapiro 1995) all constrain minorities' opportunities to attain homeownership. More recently, scholars have expanded the debate beyond disparities in attainment to stratification in returns to homeownership. Studies have established stratification in minority 
homeowners' advantages over same-race renters in residential stability and neighborhood integration (Alba, Logan, and Stults 2000), housing quality (Friedman and Rosenbaum 2004), and wealth accumulation (Flippen 2004; Krivo and Kaufman 2004). However, it is not yet known if stratification in the pathways between homeownership and health also leads to inequality in the overall homeowner health advantage.

There are compelling reasons to suspect there may also be racially stratified health returns to homeownership. The owner-renter difference in neighborhood quality, one of the potential pathways between homeownership and health, is much smaller for non-Whites (Alba et al. 2000). Segregation undermines predominantly non-White neighborhoods' economic and social integration, opportunities for geographic and socioeconomic mobility, and resources for strong community institutions and services (Massey and Denton 1993). Additionally, Black and Latino homeowners are more segregated from Whites than Black renters (Alba et al. 2000; Friedman, Tsao, and Chen 2013). As a result, non-Whites are limited in their ability to purchase homes in more advantaged areas than they could live in as renters. Similarly, Blacks and Latinos are more likely than Whites to live in crowded, low-quality housing, and the racial/ethnic difference is as large or larger among owners than renters (Friedman and Rosenbaum 2004; Rosenbaum 1996).

Further, minority homeownership is not as strongly associated with large economic advantages. This is partly because segregation and mortgage discrimination restrict many non-Whites to purchasing less valuable homes with higher interest rates (Flippen 2001; Massey and Denton 1993). Blacks' and Latinos' homes also accumulate much less equity than Whites' homes. (Boehm and Schlottmann 2008; Flippen 2004; Krivo and Kaufman 2004). Subprime lenders disproportionately target racial and ethnic minorities, particularly those with lower incomes (Rugh and Massey 2010). Higher mortgage strain and the possibility or fear of foreclosure increases the tenuousness of minority homeownership (Boehm and Schlottmann 2004; Rugh and Massey 2010). Heightened ownership insecurity has been shown to elevate mental distress, decrease self-rated health, and increase the frequency of doctor's visits (Cairney and Boyle 2004; Nettleton and Borrows 1998).

The evidence for racial/ethnic inequality in each of the proposed pathways between homeownership and health suggests minorities may exhibit a smaller homeowner health advantage than whites. This implication motivates the second hypothesis.

\section{Hypothesis 2: Minority homeowners are less likely than whites to have a significant health advantage over otherwise comparable same-race renters}

There are at least two additional questions related to these hypotheses. First, there is some debate over whether homeownership is a larger benefit or burden for many low-income households (Retsinas and Belsky 2002; Shlay 2006). Low-income homeowners experience lower than average equity appreciation and higher financial strain (Beslky and Duda 2002; Boehm and Schlottmann 2008; Herbert and Belsky 2008; Van Order and Zorn 2002). High transaction costs with selling a home may lock low-income owners into disadvantaged areas, preventing them from moving to more desirable neighborhoods, better job opportunities, or even more affordable housing options (Dietz and Haurin 2003; Retsinas and Belsky 2002). The intersection of race and class stratification may make homeownership particularly 
burdensome for low-income minority households, further undermining any potential homeownership health advantage. Conversely, homeownership is essentially a proxy for any household wealth among low-income households (Boehm and Schlottmann 2008; Oliver and Shapiro 1995). Relatively compressed economic inequality among low-income households may reduce any racial/ethnic stratification in the homeowner health advantage.

Second, the crash of the housing bubble in 2008 and 2009, and ensuing wave of foreclosures, may make the present period atypical for evaluating homeownership as a potential health resource, particularly the examination of racial/ethnic differences. Foreclosures were concentrated among low-income, and predominantly minority neighborhoods (Rugh and Massey 2010). Systematic selection of low-income minority households out of homeownership could raise the average health of minority homeowners, and lower the average health of minority renters. If so, any potential homeowner health advantage for non-whites would then be biased upward. Therefore estimates of racial/ethnic disparities in the advantage compared to whites would be biased downward, leading to a more conservative test of racial/ethnic differences in the homeowner health advantage. Additional analyses discussed later estimate the relationship between homeownership and health including years prior to the housing bubble.

\section{Methods}

\section{Current Population Survey}

Data for this study are from the March wave of the 2012 Current Population Survey (CPS). I use CPS data from the Integrated Public Use Microdata Series (IPUMS), made available by the Minnesota Population Center (King et al. 2010). The CPS collects individual information about all persons in the household from the "most knowledgeable household member," referred to as the household head. I restrict the analyses to White, Black, Latino, and Asian household heads. Household heads are the only household members for whom the general health measure is a self-report, rather than a proxy. The large, representative, and recent nature of the CPS is a clear advantage of the data because it allows for analysis of Latinos and Asians, often-overlooked groups.

\section{Health}

The dependent variable, Health, is measured by respondents' evaluations of their general health on a five-point scale, and is the only general health measure present in the CPS. Interviewers ask respondents to rate their overall health as "excellent," "very good," "good," "fair," or "poor." Self-rated health has well-established reliability and validity as a measure of general health, and is highly correlated with functional ability, morbidity, and mortality (Farmer and Ferraro 1997; Idler and Benyamini 1997; Idler and Kasl 1995). I dichotomize the variable for use with logistic regression by collapsing the responses "excellent," "very good," and "good" into good health equal to one, and "fair" and "poor" health into poor health equal to zero. This well-established practice is consistent with other forms of coding five-point self-rated health (Manor, Matthews, and Power 2000). 
As robustness checks, I analyzed dichotomous health by coding "excellent" and "very good" equal to one, and "good," "fair," and "poor" equal to zero. Second, I analyzed self-rated health as a continuous five-point variable with OLS, and as an ordered five-point variable with ordered-logistic regression. Both analyses yield substantively similar results to those presented. However, the binary operationalization of the health variable is preferable because linearity cannot be assumed for OLS. It also violates the proportional odds assumption for ordered logistic regression, as evaluated by the Brant parallel line test (Long and Freese 2006).

\section{Race/Ethnicity and Homeownership}

Race and ethnicity are coded using dichotomous variables equal to one for being Black, Latino, or Asian, all in reference to White. The CPS asks respondents to identify Hispanic or Latino origin on the basis of descent or nationality. The analyses omit non-Latino respondents identifying with multiple racial groups, which constitute very small fraction of the total sample.

The binary variable $O w n$ indicates being a homeowner relative to being a non-homeowner, hereafter referred to as renters. The CPS identifies homeowners as those who report currently owning their primary residence. Homeownership includes those with a mortgage or other loan arrangement. I examine differences in the relationship between homeownership and health across racial and ethnic groups by using separate homeownership categories for each racial/ethnic group: White Owner, Black Owner, Latino Owner, Asian Owner, Black Renter, Latino Renter, and Asian Renter. These variables measure the conditional difference in health for each group relative to White renters. The homeowner health advantage is then calculated using the difference in the predicted probabilities of good health between homeowners and same-renters.

\section{Housing-Related Characteristics}

A series of binary variables measures categorize respondents' dwellings: Mobile Home, Duplex (two single-family units), Multi-Family Dwelling (three to five single-family units), and Apt/Condo (six or more single family units), all relative to single-family detached houses.

The analyses control for residential stability and local geographic contexts with two kinds of variables. First, one-year migration status, Moved Last Yr., roughly represents residential stability by distinguishing between recent movers and longer-term residents. Second, the analyses control for city/state-level differences in housing markets, segregation, and health service provision with Metropolitan Statistical Area (MSA) or rural-by-state fixed effects. These models include binary indicators for each of the 262 MSAs and 48 rural-states of residence in the sample.

\section{Other Controls}

The analyses control for key demographic characteristics commonly associated with homeownership and health. Some of these controls might not be exogenous to health, but 
their inclusion is designed to remove potential spuriousness between homeownership and health.

Age is measured in years. Alternative analyses code age categorically with seven age categories and dummy variables for single year of age. Results do not substantively differ. I code sex with a binary variable, Female, equal to one for women. Marital status includes four binary variables, Never Married, Separated, Divorced, and Widowed, each relative to currently married. Household composition is accounted for with Number of Adults, the number of persons over 18 living in the household, Children in the Household, the number of household members under age 18, and Children Under 5, a binary indicator for the presence of any children under 5 years old. Immigrant status is measured with a series of categorical variables for the number of years since immigration, Imm $<5 \mathrm{Yrs}$, Imm $<10 \mathrm{Yrs}$, Imm $<15 \mathrm{Yrs}$, Imm $<20 \mathrm{Yrs}$, Imm $>20 \mathrm{Yrs}$. Each of these variables is in reference to being native born.

Education is coded with three binary variables, Less Than $H S$ for respondents without a high school diploma or G.E.D, Some College for those with some college education, Associate's for a technical or Associate's degree, and Bachelor's for those with a Bachelor's degree or higher. The reference category is having a high school diploma or G.E.D. Binary variables Unemployed and Out of Labor Force are in reference to employment. The measure of income, Log HH Income, is the logged value of total household income from all sources, including wages, private transfers, and public assistance. Household income is also adjusted for household size by dividing by the square root of the number of household members (Brady 2009). Finally, the dichotomous variable Private Insurance indicates health insurance provided by employers or individually purchased, and Public Insurance includes coverage through Medicaid or Medicare. Both are in reference to being uninsured.

\section{Analytic Strategy}

This study tests the hypothesis that homeowners have a robust health advantage by comparing the probabilities of good health between renters and owners, and then tests the hypothesis of racial stratification by comparing the owner-renter health difference between racial and ethnic groups. I first descriptively compare the prevalence of good health between homeowners and renters across each racial and ethnic group. I then use logistic regression to make the same comparison when conditioning on observable factors. The regression models include sampling weights provided by the Census Bureau to adjust for the sampling design. Finally, I conduct a variety of additional analyses to test variability in the relationship for low-income households, to limit potential reverse causation, and to examine potential variation over time.

\section{Results \\ Descriptive Patterns}

Table 1 presents descriptive statistics for the analytic sample, by race/ethnicity. There are significant racial/ethnic disparities in health $(\mathrm{p}<0.001$ for a Chi-square test between each group except between Whites and Latinos). Black heads report the worst health, and Asians 
report the best health. There are also significant disparities in homeownership ( $\mathrm{p}<0.01$ for a Chi-square test between each group except between Blacks and Latinos). Nearly three out of four White household heads own their homes. In contrast, fewer than half of Black and Latino household heads and fewer than two of three Asian heads own their homes.

Table 2 shows the cross-tabulations of the proportion of respondents reporting good health in each racial/ethnic group by homeownership status. The third column presents the ownerrenter difference in the prevalence of good health. The asterisks denote the statistical significance levels of Chi-square tests between owners and renters within each racial/ethnic group.

Among all households, the proportion of households reporting good health is 3.5 percentage-points higher among homeowners than renters. Among Whites, the difference is 3.7 percentage points. The differences are much smaller for Black and Asian households, approximately 2 percentage points, and significant at the 0.05 level only for Blacks. The difference for Latino households is less than one percentage point, and not statistically significant. Overall, Asians report the best health, followed by White owners. Black household heads report the worst health.

Clearly, an array of relevant demographic and socioeconomic characteristics influences these patterns. However, these unadjusted estimates demonstrate meaningful variation in the distribution of good health by homeownership status and race/ethnicity in the population.

\section{Regression Results}

Table 3 presents logistic regression results of self-rated health on homeownership, housingrelated characteristics, and race and ethnicity. The estimates are presented as the marginal effect of the each variable, with all other variables held constant at their means. The marginal effect for categorical variables is simply the difference in the predicted probability of good health compared to the reference group. The marginal effect of continuous variables is the change in the predicted probability of good health for small differences in the independent variable.

Consistent with past research, recent immigrants, those with higher education, income, and private insurance have higher probabilities of good health. Women also have higher probabilities of good health, consistent with the upward trend in women's self-rated health over time (Schnittker 2007). This gender difference may also be an artifact of how the CPS selects the most knowledgeable household member as the household head. Also consistent with previous findings, older age and all non-married statuses are associated with lower probabilities of good health.

Model 1 in Table 3 shows homeowners have higher probabilities of good health than renters by 2.5 percent, net of controls. Both Black and Asian household heads have significantly lower probabilities of good health than White heads. There is no significant difference between Whites and Latinos.

Model 2 adds the housing-related variables to the regression from Model 1. These controls help to avoid some potential confounding between the homeowner health advantage and 
some of the indirect benefits of homeownership. Recent movers have significantly higher probabilities of good health, possibly due to health selection into moving. Residents of single-family detached houses have higher probabilities of reporting good health than those living in mobile homes, but no significant difference with other housing types.

The most notable result from Model 2 is the robust homeowner health advantage, which is slightly larger with housing-related controls. The 3.1 percent advantage in Model 2 is larger than the conditional difference between Whites and any minority group. It is as large as the difference between those with less-than-high school education and high school, and almost as large as the conditional difference between the married and the divorced.

Results from Models 3 and 4 show the pattern for racial/ethnic-homeownership group relative to White renters. The pattern of results is highly consistent with or without housingrelated controls. The results for all control variables are also consistent with those in the previous models. The differences between owners and renters, and between racial/ethnic groups, are somewhat difficult to assess in the table because the marginal effects are all relative to White renters. To ease interpretation, I present the predicted probabilities of good health in Figure 1. The right side presents the predicted probabilities for homeowners and renters by racelethnicity, estimated by Model 4 in Table 3. For comparison, the left side presents the predicted probabilities for homeowners and renters overall, estimated by Model 2 in Table 3. All control variables are held constant at their means, removing the effect of observable compositional differences between groups.

The predicted probability of good health for White homeowners is $3.7 \%$ higher than for comparable renters, larger than the $3.1 \%$ difference estimated for the total sample. The homeowner-renter difference is also statistically significant among Black households, but is much smaller at 2.3\%. The differences for Latino and Asian homeowners compared to renters are $1.2 \%$ and $1.9 \%$ respectively. Neither difference is statistically significant. These owner-renter differences are also presented in the first column of Table 4, below.

Another clear finding illustrated in Figure 1 is the substantially health advantage of White homeowners over all other groups. White homeowners' predicted probability of good health is statistically significantly higher than all other groups by 2.2 to 6.0 percent, and all differences are statistically significant. White renters, however, are only significantly healthier compared to Black renters, and are significantly less healthy than Latino owners.

Overall, the results of Models 1 and 2 support Hypothesis 1, that homeowners experience a significant health advantage over renters. The size of this health difference is comparable to differences by education and marital status. The results of Models 3 and 4 support

Hypothesis 2, that the homeowner health advantage is stratified by race and ethnicity. White homeowners experience a substantial health advantage over White renters. Black homeowners experience a smaller, but statistically significant health advantage. The ownerrenter differences for Asians and Latinos are not significant. 


\section{Additional Analyses}

As discussed above, there are reasons to expect that homeownership for low-income households may be a greater burden than benefit (Shlay 2006). Race and class stratification may also intersect, intensifying any potential burden for minority homeowners. I test the relationship between homeownership and health among low-income households by reestimating Model 2 and 4 of Table 3. The sample includes households with equivalized income below half of the median. The results are presented in the second column of Table 4 as the difference in the predicted probabilities between homeowners and same-race renters, with all controls held constant at the means. The first column displays these predicted differences from Models 2 (above) and 4 (below), from Table 3, for comparison.

Despite potential burdens, the health advantage for low-income homeowners over renters is almost twice the size of the difference in the total sample, 6.0 compared to 3.1 percent. The homeowner health advantages among each racial/ethnic group are much larger among the low-income sample than the total sample, and statistically significant for White, Black, and Asian households (marginally significant for Latinos with p slightly greater than 0.05). Homeownership appears to be much more salient to health among low-income households than on average. Moreover, racial/ethnic stratification in the homeowner health advantage is relatively lower.

Table 4 also presents the results of additional analyses designed to limit reverse causation. These models examine health variation among respondents who are presumably not too physically limited to achieve or maintain homeownership. First, I re-estimate Models 2 and 4 from Table 2, excluding disabled respondents (those with any functional limitations, or difficulties with activities of daily living or instrumental activities of daily living). Second, I exclude household heads with "poor" or "fair" self-rated health. The regression in the third column of Table 4 predicts "very good" or "excellent" self-rated health relative to "good" health. Finally, I exclude household heads that moved in the previous year in the final column of Table 4 . This limitation increases the probability that homeownership status is determined temporally prior to health status.

The pattern of results is similar to the main results. The owner-renter health differences are smaller without disabled household heads, but the pattern of statistical significance is the same. White homeowners exhibit a significant health advantage over White renters in all models. Black homeowners have a smaller but significant health advantage over Black renters, but have a non-significant health disadvantage when excluding the disabled and poor/fair health. The owner-renter health differences among Latino and Asian households are not statistically significant in any model.

Finally, extended consequences of the housing crisis might lead one to suspect atypical selection effects bias the results shown here, as discussed above. Unhealthy individuals may have been disproportionately selected out of homeownership through foreclosure, artificially exaggerating the size of the homeowner health advantage. However, the results shown here are consistent with those using the March CPS since 1996, the first year including the selfrated health measure. Additional analyses examined a pooled sample of household heads from 1996 to 2012. A logistic regression model with categorical variables for race/ethnicity- 
homeownership status-year estimates the time trends in the predicted probability of good health for each group. The predicted probabilities of good health by race/ethnicity and homeownership status over time are presented in Figure A.1 in the Appendix. There is some fluctuation in the homeowner advantage, but there is no clear and significant time trend in the homeowner-renter health difference. Overall, the patterns observed in the 2012 CPS are typical of the patterns since 1996.

\section{Discussion}

The results of this study point to several conclusions. First, homeowners have a significant health advantage over renters, on average. In the total sample, homeowners have higher probabilities of good health by 2.5 percent. The homeowner advantage is even larger, 3.1 percent, when adjusting for an array of demographic, socioeconomic, and housing-related characteristics. This finding clearly supports Hypothesis 1, that homeownership represents a significant health resource.

Second, disaggregating the relationship between homeownership and health reveals large racial and ethnic disparities. White homeowners have almost four percent higher probabilities of good health than comparable White renters. Black homeowners also exhibit a health advantage over Black renters, but the advantage is smaller than among Whites. There is little evidence that Latino and Asian homeowners experience a significant advantage. These patterns support Hypothesis 2, that homeownership's significance as a health resource is stratified by race and ethnicity.

An unanticipated finding of this study is racial/ethnic health disparities are relatively small among renting household heads. Black renters are less healthy than White and Latino renters, but no other racial differences among renters are statistically significant. Most notably, Figure 1 suggests these relative disparities are small because the health advantage for Whites is concentrated among homeowners, and not renters. White homeowners exhibit an exceptionally high predicted probability of good health, significantly greater than all other groups.

The results also suggest homeownership is a particularly salient health resource among lowincome households (see Table 4). It is possible that selection of unhealthy household heads out of homeownership is more prevalent in this sample. However, homeownership is also effectively a proxy for the presence of any household wealth among low-income households (Herbert and Belsky 2008). Homeownership's positive effects on individuals' sense of control and mental health may also be particularly salient relative to low-income renters (Manturuk 2012). Contrary to expectations that race and class inequality intersect to particularly burden low-income minority homeowners, homeowners of all racial/ethnic groups exhibit a significant health advantage over same-race renters.

Beyond the empirical results, this study emphasizes the relevance of racial/ethnic inequality in both access to and returns from important socioeconomic resources. Both the significant health advantage for homeowners compared to renters, and the significant disadvantages for minorities relative to Whites, are consistent with fundamental cause theory. However, the 
findings of this study support the argument that racial stratification affects health profoundly enough to undermine homeownership's health advantages. This stratification is similar to racial disparities in the health benefits of other key socioeconomic resources (Crimmins 2004). This theoretical and methodological perspective advances the sociological understanding of racial stratification beyond attempts to "explain away" residual racial disparities, and toward an understanding of the interactive processes generating inequalities (Brown 2003; James 2008). Racial and ethnic stratification generates barriers both to nonWhites' attainment of salient socioeconomic resources, and the degree to which they can translate these resources into health advantages.

Future research can build on the present analysis by addressing some limitations of the data used here. One advantage of the CPS is the large sample size that allows for racial/ethnic and income decompositions. However, the cross-sectional nature of the data represents an empirical limitation. As previously discussed, it is possible that poor health impairs individuals' abilities for socioeconomic and homeownership attainment. Additionally, the CPS unfortunately lacks measures of wealth. This and other measures for the potential pathways may help determine the mechanisms for homeownership's stratified health benefits. Aside from mechanisms however, future research in the fundamental cause tradition should examine health disparities as products of both inequality in access to socioeconomic resources, and stratification in their health benefits.

\section{References}

Alba, Richard; Logan, John; Stults, Brian. How segregated are middle-class African Americans? Social Problems. 2000; 47:543-558.

Beslky, Eric; Duda, Mark. Asset Appreciation, Timing of Purchases and Sales, and Returns to LowIncome Homeownership. In: Retsinas, N.; Belsky, E., editors. Low-Income Homeownership: Examining the Unexamined Goal. Washington D.C: The Brookings Institute; 2002.

Boehm, Thomas; Schlottmann, Alan. The Dynamics of Race, Income, and Homeownership. Journal of Urban Economics. 2004; 55:113-130.

Boehm, Thomas; Schlottmann, Alan. Wealth Accumulation and Homeownership: Evidence for LowIncome Households. Cityscape. 2008; 10:225-256.

Brady, David. Rich Democracies, Poor People: How Politics Explain Poverty. New York: Oxford University Press; 2009.

Brown, Tony. Critical Race Theory Speaks to the Sociology of Mental Health: Mental Health Problems Produced by Racial Stratification. Journal of Health and Social Behavior. 2003; 44:291301.

Browning, Christopher; Cagney, Kathleen. Neighborhood Structural Disadvantage, Collective Efficacy, and Self-Rated Physical Health in an Urban Setting. Journal of Health and Social Behavior. 2002; 43:383-399. [PubMed: 12664672]

Cairney, John; Boyle, Michael. Home Ownership, Mortgages, and Psychological Distress. Housing Studies. 2004; 19:161-174.

Crimmins, Eileen. Trends in the Health of the Elderly. Annual Review of Sociology. 2004; 25:79-98.

Dietz, Robert; Haurin, Donald. The Social and Private Micro-Level Consequences of Homeownership. Journal of Urban Economics. 2003; 54:401-450.

Dunn, James. Housing and Health Inequalities: Review and Prospects for Research. Housing Studies. 2000; 15:341-366.

Entwisle, Barbara. Putting People into Place. Demography. 2007; 44:687-703. [PubMed: 18232206]

Evans, Gary; Wells, Nancy; Chan, Hoi-Yan Erica; Saltzman, Heidi. Housing Quality and Mental Health. Journal of Consulting and Clinical Psychology. 2000; 68:526-530. [PubMed: 10883571] 
Evans, Gary; Wells, Nancy; Moch, Annie. Housing and Mental Health: A Review of the Evidence and a Methodological and Conceptual Critique. Journal of Social Issues. 2003; 59:475-500.

Farmer, Melissa; Ferraro, Kenneth. Distress and Perceived Health: Mechanisms of Health Decline. Journal of Health and Social Behavior. 1997; 39:298-311. [PubMed: 9343966]

Flippen, Chenoa. Residential Segregation and Minority Homeownership. Social Science Research. 2001; 30:337-362.

Flippen, Chenoa. Unequal Returns to Housing Investments? A Study of Real Housing Appreciation among Black, White, and Hispanic Households. Social Forces. 2004; 82:1527-1555.

Friedman, Samantha; Rosenbaum, Emily. Nativity Status and Racial/Ethnic Differences in Access to Quality Housing: Does Homeownership Bring Greater Parity? Housing Policy Debate. 2004; 15:865-901.

Friedman, Samantha; Tsao, HS.; Chen, Cheng. Housing Tenure and Residential Segregation in Metropolitan America. Demography. 2013; 50:1477-1498. [PubMed: 23292639]

Herbert, Christopher; Belsky, Eric. The Homeownership Experience of Low-Income and Minority Households: A Review and Synthesis of the Literature. Cityscape. 2008; 10:5-60.

Idler, Ellen; Benyamini, Y. Self-Rated Health and Mortality: A Review of Twenty-Seven Community Studies. Journal of Health and Social Behavior. 1997; 38:21-37. [PubMed: 9097506]

Idler, Ellen; Kasl, S. Self-Ratings of Health: Do They Also Predict Change in Functional Ability? Journal of Gerontology. 1995; 50B

James, Angela. Making Sense of Race and Racial Classification. In: Zuberi, T.; Bonilla-Silva, E., editors. White Logic, White Methods: Racism and Methodology. Lanham, MD: Rowman and Littlefield; 2008. p. 31-45.

Kawachi, Ichiro; Berkman, Lisa. Neighborhoods and Health. New York: Oxford University Press; 2003.

Kearns, Ade; Hiscock, Rosemary; Ellway, Anne; Macintyre, Sally. 'Beyond Four Walls.' The PsychoSocial Benefits of Home: Evidence from West Central Scotland. Housing Studies. 2000; 15:387410.

King, Miriam; Ruggles, Steven; Trent Alexander, J.; Flood, Sarah; Genadek, Katie; Schroeder, Matthew; Trampe, Brandon; Vick, Rebecca. Integrated Public Use Microdata Series, Current Population Survey: Version 3.0 [Machine-Readable Database]. Minneapolis, MN: University of Minnesota; 2010.

Kirby, James. Poor People, Poor Places and Access to Health Care in the United States. Social Forces. 2008; 87:325-355.

Krivo, Lauren; Kaufman, Robert. Housing and Wealth Inequality: Racial-Ethnic Differences in Home Equity in the United States. Demography. 2004; 41:585-605. [PubMed: 15461016]

Link, Bruce; Phelan, Jo. Social Conditions as Fundamental Causes of Disease. Journal of Health and Social Behavior. 1995; 35:80-94. [PubMed: 7560851]

Long, Scott; Freese, Jeremy. Regression Models for Categorical Dependent Variables Using Stata. 2. College Station, TX: Stata Press; 2006.

Macintyre, Sally; Ellaway, Anne. Neighborhoods and Health: An Overview. In: Kawachi, I.; Berkman, L., editors. Neighborhoods and Health. New York: Oxford University Press; 2003. p. 20-44.

Macintyre, Sally; Ellaway, Anne; Der, G.; Greaeme, F.; Hunt, K. Do Housing Tenure and Car Access Predict Health because They Are Simply Markers of Income or Self-Esteem? A Scottish Study. Journal of Epidemiology and Community Health. 1998; 52:657-664. [PubMed: 10023466]

Manor, Orly; Matthews, Sharon; Power, Chriss. Dichotomous or Categorical Response? Analyzing Self-Rated Health and Lifetime Social Class. International Journal of Epidemiology. 2000; 29:149-157. [PubMed: 10750617]

Manturuk, Kim. Urban Homeownership and Mental Health: Mediating Effect of Perceived Sense of Control. City and Community. 2012; 11:409-430.

Massey, Douglass; Denton, Nancy. American Apartheid: Segregation and the Making of the Underclass. Cambridge, MA: Harvard University Press; 1993.

McCabe, Brian. Are Homeowners Better Citizens? Homeownership and Community Participation in the United States. Social Forces. 2013; 91:929-954. 
Nettleton, Sarah; Borrows, Roger. Mortgage Debt, Insecure Homeownership and Health: An Exploratory Analysis. Sociology of Health \& Illness. 1998; 20:25-30.

Oliver, Melvin; Shapiro, Thomas. Black Wealth/White Wealth: A New Perspective on Racial Inequality. New York: Routledge; 1995.

Pollack, Craig; Chideya, Sekai; Cubbin, Catherine; Williams, Brie; Dekkar, Mercedes; Braveman, Paula. Should Health Studies Measure Wealth? A Systematic Review. American Journal of Preventative Medicine. 2007; 33:250-264.

Retsinas, Nicolas; Belsky, Eric. Low-Income Homeownership: Examining the Unexamined Goal. Washington, D.C: The Brookings Institution; 2002.

Rohe, William; Stegman, Michael. The Effects of Homeownership on the Self-Esteem, Perceived Control and Satisfaction of Low-Income People. Journal of the American Planning Association. 1994a; 20:173-84.

Rohe, William; Stegman, Michael. The Impact of Homeownership on the Social and Political Involvement of Low-Income People. Urban Affairs Quarterly. 1994b; 30:152-172.

Rohe, William; Stewart, Leslie. Homeownership and Neighborhood Stability. Housing Policy Debate. 1996; 7:27-78.

Rohe, William; Van Zandt, Shannon; McCarthy, George. Home Ownership and Access to Opportunity. Housing Studies. 2002; 17:51-61.

Rosenbaum, Emily. Racial/Ethnic Differences in Home Ownership and Housing Quality, 1991. Social Problems. 1996; 43:403-426.

Rossi, Peter; Weber, Eleanor. The Social Benefits of Homeownership: Empirical Evidence from National Surveys. Housing Policy Debate. 1996; 7:1-35.

Rugh, Jacob; Massey, Douglas. Racial Segregation and the American Foreclosure Crisis. American Sociological Review. 2010; 75:629-651. [PubMed: 25308973]

Sampson, Robert. Neighborhood-Level Context and Health: Lessons from Sociology. In: Kawachi, I.; Berkman, L., editors. Neighborhoods and Health. New York: Oxford University Press; 2003. p. 132-146.

Sampson, Robert; Morenoff, Jeffrey; Gannon-Rowley, Thomas. Assessing "Neighborhood Effects": Social Processes and New Directions in Research. Annual Review of Sociology. 2002; 28:443478.

Schnittker, Jason. Working More, Feeling Better: Women's Health, Employment, and Family Life, 1974-2004. American Sociological Review. 2007; 72:221-238.

Shlay, Anne. Low-Income Homeownership: American Dream or Delusion? Urban Studies. 2006; 43:511-513.

U.S. Census Bureau. Residential Vacancies and Homeownership in the Fourth Quarter 2012. U.S. Census Bureau; 2013.

Van Order, Robert; Zorn, Peter. Performance of Low-Income and Minority Mortgages. In: Retsinas, N.; Belsky, E., editors. Low-Income Homeownership: Examining the Unexamined Goal. Washington, D.C: The Brookings Institute; 2002.

Yinger, John. Closed Doors, Opportunities Lost: the Continuing Costs of Housing Discrimination. New York: Russell Sage Foundation; 1995. 


\section{APPENDIX}
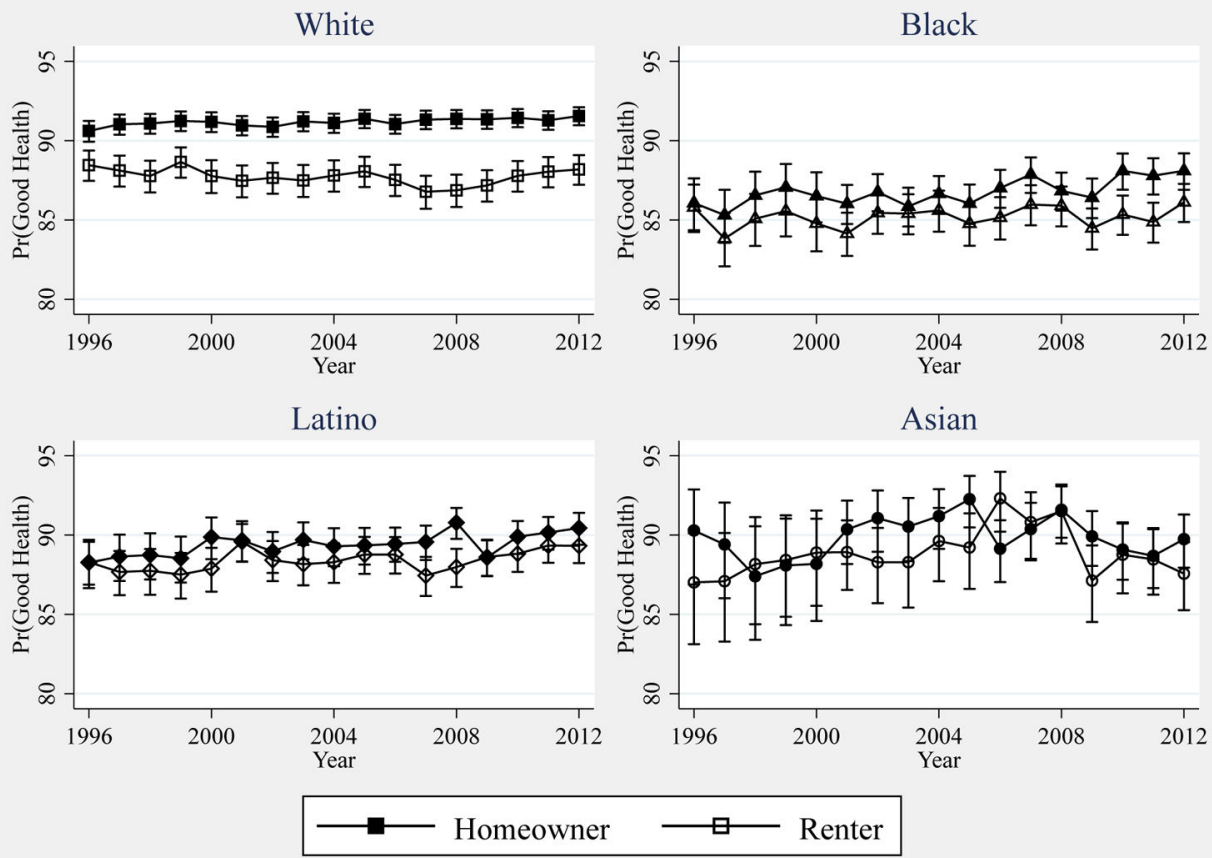

Figure A.1.

Predicted Probability of Good Health by Race/Ethnicity and Homeownership Status, with 95\% Confidence Intervals.

Note: The predicted probabilities are calculated using estimates from a re-estimation of Model 4 in Table 3, but with separate indicators for respondents' race/ethnicityhomeownership status-year. The model includes all housing characteristics and control variables, and the predicted probabilities are calculated with these variables held constant at their means for the total sample. 


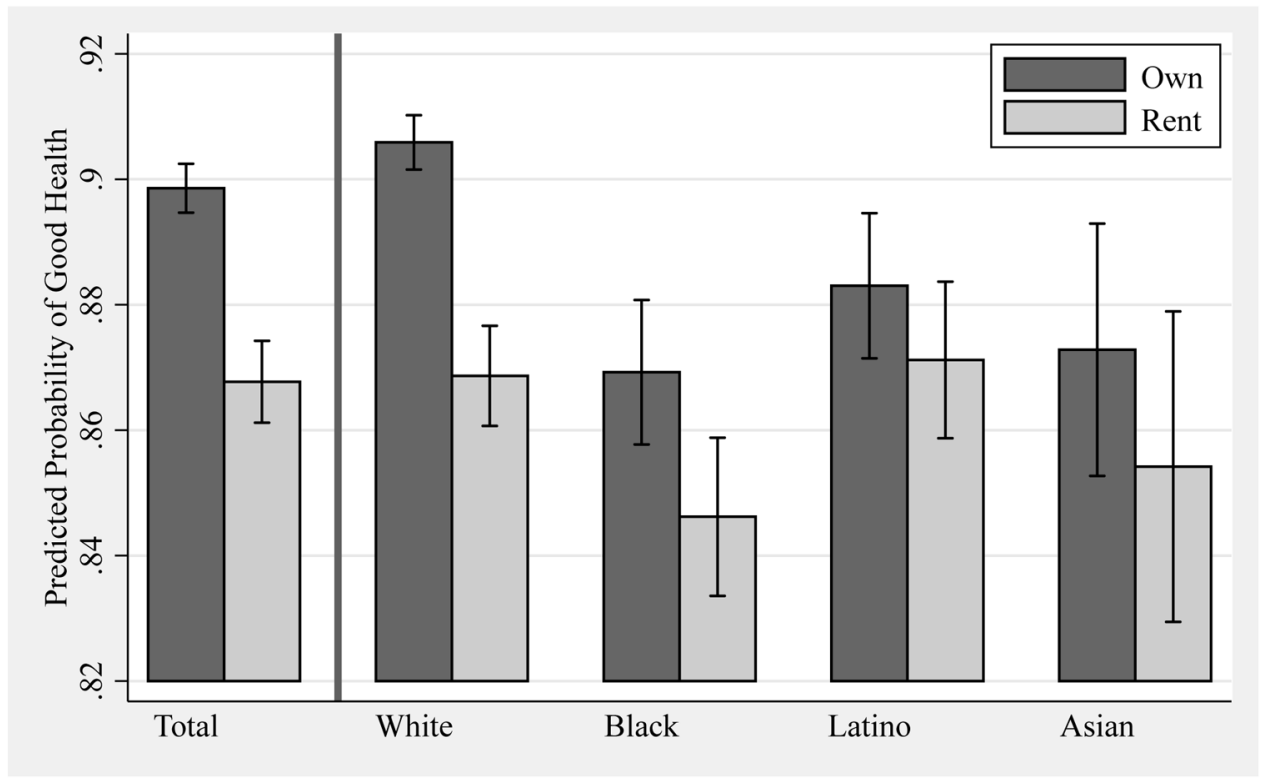

Figure 1.

Predicted Probability of Good Health by Race/Ethnicity and Homeownership, with 95\% Confidence Intervals.

Notes: Predicted probabilities for all households (left) are calculated using estimates from Model 2, Table 3; probabilities by race/ethnicitity (right) are calculated using estimates from Model 4, Table 3. All control variables are held constant at the sample means. The homeownership advantage is significant for the total sample (left), and White and Black households (right). White homeowners have significantly higher probabilities of good health than all other groups. Black renters have significantly lower probabilities than White and Latino homeowners and renters. 


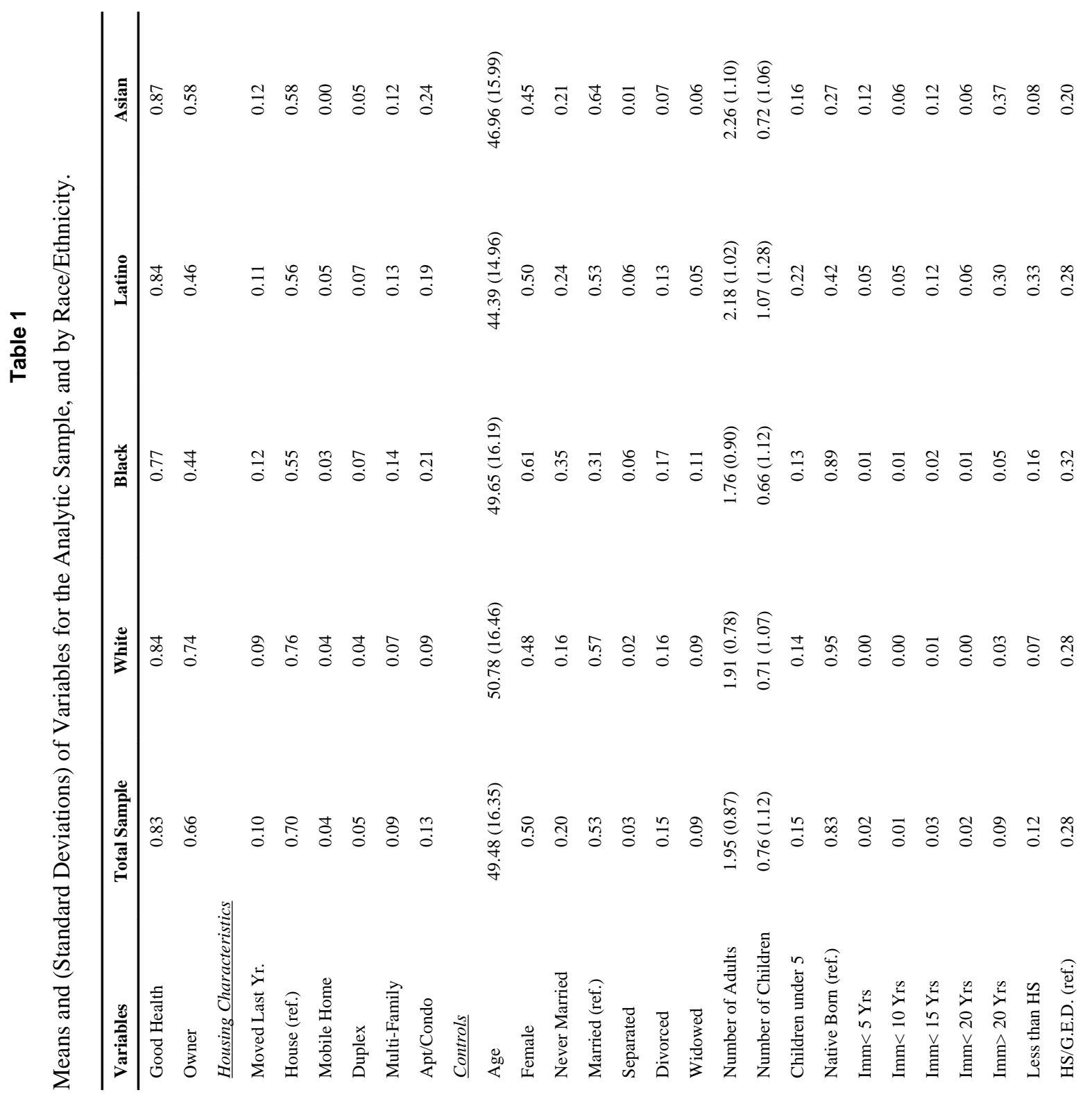




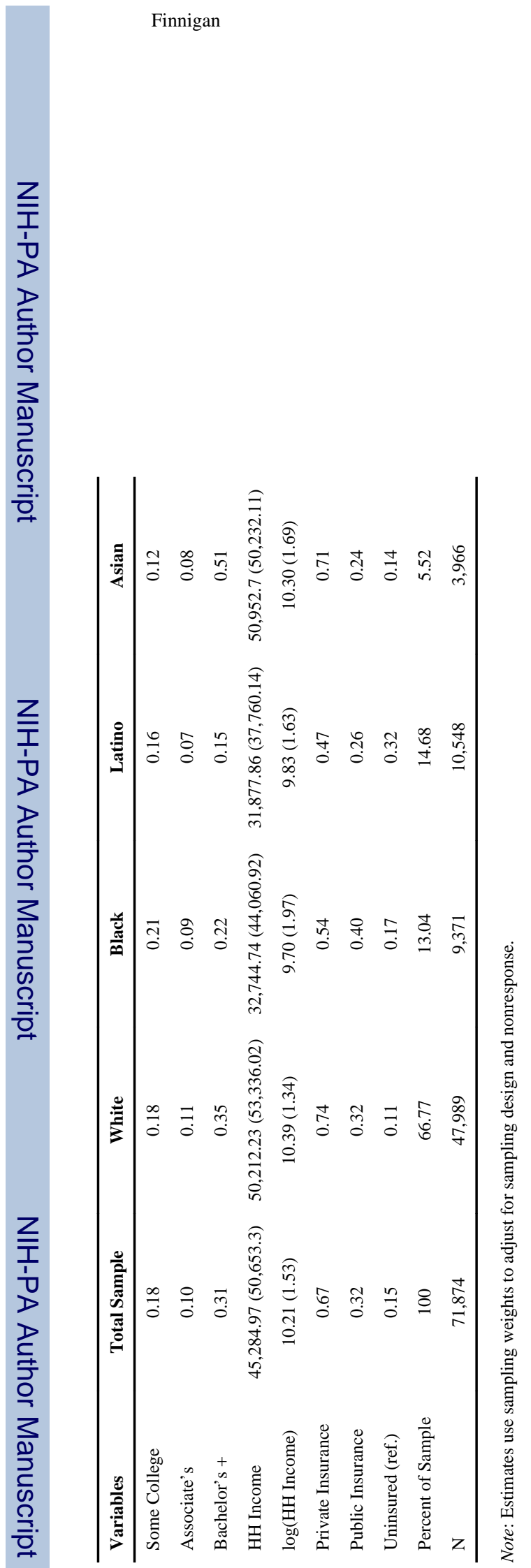

Page 19

Soc Sci Med. Author manuscript; available in PMC 2015 January 21. 


\section{Table 2}

Prevalence of Good Health by Race/Ethnicity and Homeownership Status.

\begin{tabular}{llll}
\hline & Owner & Rent & Owner - Rent \\
\cline { 2 - 4 } Total & $\mathbf{0 . 8 4 3}$ & $\mathbf{0 . 8 0 8}$ & $\mathbf{0 . 0 3 5}$ \\
\hline White & 0.848 & 0.811 & $0.037^{* * *}$ \\
Black & 0.780 & 0.760 & $0.020^{*}$ \\
Latino & 0.841 & 0.834 & 0.007 \\
Asian & 0.884 & 0.861 & $0.023^{+}$ \\
\hline
\end{tabular}

Note: Estimates use sampling weights to adjust for sampling design and nonresponse.

$* * *$ $\mathrm{p}<0.001$

$* *<0.01$,

p $<0.05$, and

${ }_{\mathrm{p}}<0.10$ denote Chi-Squared significance levels. 
Table 3

Logistic Regression for Good Health on Homeownership among the Total Sample, Presented as Marginal Effects and (t-statistics).

\begin{tabular}{|c|c|c|c|c|}
\hline Variables & Model 1 & Model 2 & Model 3 & Model 4 \\
\hline Owner (ref = Renter) & $0.025^{* * *}(7.19)$ & $0.031^{* * *}(7.66)$ & & \\
\hline Black (ref = White) & $-0.030^{* * *}(-7.88)$ & $-0.028^{* * *}(-7.13)$ & & \\
\hline Latino $($ ref = White $)$ & $-0.004(-0.91)$ & $-0.011^{*}(-2.19)$ & & \\
\hline Asian (ref = White) & $-0.019^{*}(-2.55)$ & $-0.025^{* * *}(-3.32)$ & & \\
\hline White Owner (ref = White Renter) & & & $-0.022^{* *}(-3.27)$ & $-0.022^{* *}(-3.27)$ \\
\hline Black Owner (ref = White Renter) & & & $0.012(1.80)$ & $0.003(0.35)$ \\
\hline Latino Owner (ref = White Renter) & & & $-0.007(-0.54)$ & $-0.014(-1.10)$ \\
\hline Asian Owner (ref = White Renter) & & & $0.033^{* * *}(7.77)$ & $0.037^{* * *}(8.03)$ \\
\hline Black Renter (ref $=$ White Renter) & & & $-0.008(-1.18)$ & $0.001(0.08)$ \\
\hline Latino Renter (ref = White Renter) & & & $0.016^{*}(2.43)$ & $0.014(1.95)$ \\
\hline Asian Renter (ref $=$ White Renter) & & & $0.007(0.69)$ & $0.004(0.37)$ \\
\hline Moved Last Yr. (1 = yes) & & $0.012 *(2.43)$ & & $0.012 *(2.44)$ \\
\hline Mobile Home (ref = House) & & $-0.045^{* * *}(-7.53)$ & & $-0.044^{* * *}(-7.46)$ \\
\hline Duplex (ref = House) & & $-0.009(-1.49)$ & & $-0.009(-1.49)$ \\
\hline Multi-Family (ref = House) & & $0.003(0.61)$ & & $0.003(0.54)$ \\
\hline Apt/Condo $($ ref = House $)$ & & $-0.009(-1.84)$ & & $-0.009(-1.92)$ \\
\hline Age & $-0.001^{* * *}(-8.79)$ & $-0.001^{* * *}(-9.77)$ & $-0.001^{* * *}(-8.86)$ & $-0.001^{* * *}(-9.82)$ \\
\hline Female $($ ref $=$ Male $)$ & $0.010^{* * *}(3.54)$ & $0.009^{* *}(3.28)$ & $0.010^{* * *}(3.52)$ & $0.009^{* *}(3.27)$ \\
\hline Never Married (ref = Married) & $-0.000(-0.03)$ & $-0.004(-0.78)$ & $-0.000(-0.03)$ & $-0.003(-0.74)$ \\
\hline Separated (ref = Married) & $-0.047^{* * *}(-6.63)$ & $-0.045^{* * *}(-6.45)$ & $-0.047^{* * *}(-6.65)$ & $-0.045^{* * *}(-6.45)$ \\
\hline Divorced (ref = Married) & $-0.041^{* * *}(-9.90)$ & $-0.039^{* * *}(-9.43)$ & $-0.040^{* * *}(-9.60)$ & $-0.038^{* * *}(-9.17)$ \\
\hline Widowed (ref = Married) & $-0.003(-0.65)$ & $-0.003(-0.66)$ & $-0.002(-0.46)$ & $-0.002(-0.48)$ \\
\hline Number of Adults & $-0.011^{* * *}(-6.14)$ & $-0.011^{* * *}(-6.54)$ & $-0.010^{* * *}(-5.90)$ & $-0.011^{* * *}(-6.33)$ \\
\hline Number of Children & $0.008^{* * *}(4.51)$ & $0.008^{* * *}(4.50)$ & $0.008^{* * *}(4.43)$ & $0.008^{* * *}(4.44)$ \\
\hline Children under 5 ( 1 = yes $)$ & $0.039^{* * *}(6.80)$ & $0.038^{* * *}(6.78)$ & $0.039^{* * *}(6.78)$ & $0.038^{* * *}(6.76)$ \\
\hline Imm $<5$ Yrs (ref = Native Born $)$ & $0.053^{* * *}(4.17)$ & $0.047^{* * *}(3.72)$ & $0.049^{* * *}(3.84)$ & $0.043^{* * *}(3.41)$ \\
\hline Imm $<10$ Yrs (ref = Native Born) & $0.051^{* * *}(3.93)$ & $0.046^{* * *}(3.58)$ & $0.048^{* * *}(3.68)$ & $0.043^{* * *}(3.36)$ \\
\hline Imm $<15$ Yrs (ref = Native Born) & $0.028^{* *}(2.96)$ & $0.021^{*}(2.30)$ & $0.026^{* *}(2.74)$ & $0.020^{*}(2.12)$ \\
\hline Imm $<20$ Yrs (ref = Native Born) & $0.018(1.65)$ & $0.012(1.08)$ & $0.018(1.62)$ & $0.012(1.08)$ \\
\hline Imm> 20 Yrs (ref = Native Born) & $0.011^{*}(2.11)$ & $0.003(0.65)$ & $0.012^{*}(2.24)$ & $0.004(0.83)$ \\
\hline Less than HS (ref = HS/GED) & $-0.035^{* * *}(-8.81)$ & $-0.030^{* * *}(-7.75)$ & $-0.035^{* * *}(-8.80)$ & $-0.030^{* * *}(-7.76)$ \\
\hline Some College (ref = HS/GED) & $0.019^{* * *}(4.87)$ & $0.016^{* * *}(4.19)$ & $0.019^{* * *}(4.93)$ & $0.016^{* * *}(4.22)$ \\
\hline Associate's (ref = HS/GED) & $0.016^{* *}(3.11)$ & $0.012^{*}(2.39)$ & $0.016^{* *}(3.17)$ & $0.012 *(2.43)$ \\
\hline Bachelor's + (ref = HS/GED) & $0.060^{* * *}(15.14)$ & $0.051^{* * *}(12.96)$ & $0.060^{* * *}(15.17)$ & $0.052^{* * *}(12.99)$ \\
\hline
\end{tabular}




\begin{tabular}{lcccc}
\hline Variables & Model 1 & Model 2 & Model 3 & Model 4 \\
\hline Unemployed & $-0.025^{* * *}(-3.63)$ & $-0.024^{* * *}(-3.65)$ & $-0.025^{* * *}(-3.68)$ & $-0.025^{* * *}(-3.68)$ \\
Not in Labor Force & $-0.122^{* * *}(-34.47)$ & $-0.119^{* * *}(-33.95)$ & $-0.122^{* * *}(-34.48)$ & $-0.119^{* * *}(-33.97)$ \\
$\log$ (HH Income) & $0.006^{* * *}(7.05)$ & $0.005^{* * *}(6.54)$ & $0.006^{* * *}(7.10)$ & $0.005^{* * *}(6.59)$ \\
Private Insurance (ref = uninsured) & $0.055^{* * *}(17.96)$ & $0.052^{* * *}(17.12)$ & $0.055^{* * *}(17.85)$ & $0.052^{* * *}(17.05)$ \\
Public Insurance (ref = uninsured) & $-0.059^{* * *}(-16.10)$ & $-0.058^{* * *}(-16.02)$ & $-0.060^{* * *}(-16.22)$ & $-0.059^{* * *}(-16.12)$ \\
Area F.E. & No & Yes & No & Yes \\
Observations & 71,874 & 71,874 & 71,874 & 71,874 \\
BIC & $-7,123$ & $-4,093$ & $-7,108$ & $-4,073$ \\
\hline
\end{tabular}

Notes: Robust t-statistics in parentheses. Reference categories for binary variables indicated after variable names. BIC' indicates the model fit relative to the null model; more negative numbers indicate better model fit.

$* * *$

$\mathrm{p}<0.001$,

**

$<0.01$, and

$\mathrm{p}<0.05$ (two-tailed test) 


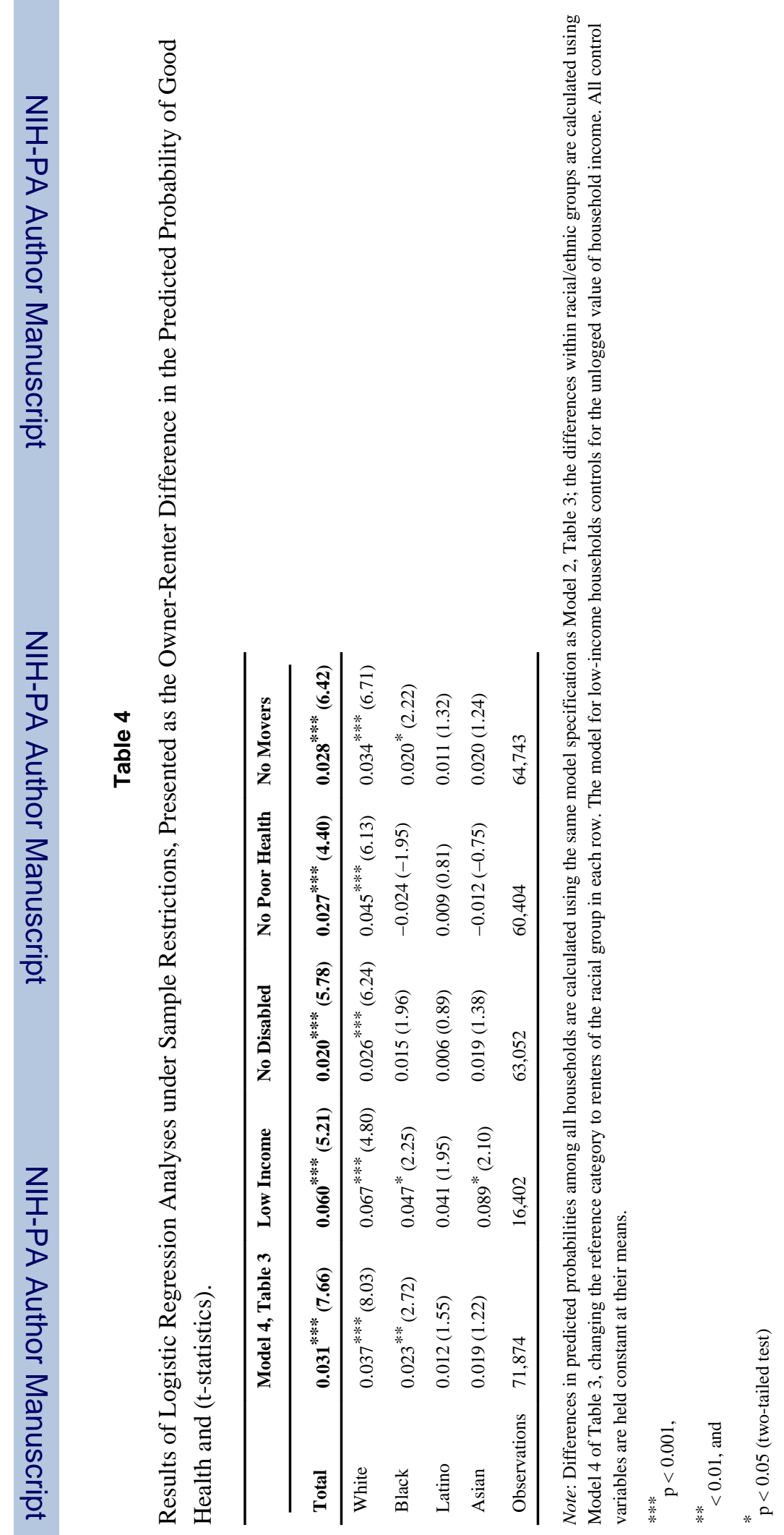

Soc Sci Med. Author manuscript; available in PMC 2015 January 21. 